\title{
Mensaje de toma de posesión del doctor Mauricio Hernández Avila
}

E n 1981 inicié mis labores en la Secretaría de Salud como residente de patología del Instituto Nacional de Nutrición Salvador Zubirán. En esa misma época tuve la oportunidad de trabajar con los colegas y amigos de la División de Nutrición de Comunidad, quienes abrieron para mí las puertas del mágico mundo de la salud pública. En esa época descubrí el gran potencial que podría tener el culto a Hygea y deserté, definitivamente, de Panacea; inicié así el tránsito de la patología a la salud pública.

Gracias al Consejo Nacional de Ciencia y Tecnología y a los esfuerzos de mis padres -que por cierto fue la primera mezcla de financiamiento público y privado que experimenté- pude obtener una educación formal en epidemiología en la Escuela de Salud Pública de Harvard. Debo mencionar que no pude resistir el canto de las sirenas nacionales y decidí incorporarme a un grupo de jóvenes que tenía un sueño generacional ahora llamado Instituto Nacional de Salud Pública (INSP).

Ingresé al INSP hace exactamente 13 años. A lo largo de este tiempo he crecido, madurado y me he consolidado como un profesional de la salud pública gracias a las ricas y estimulantes interacciones que he tenido con su comunidad, en especial al compromiso y la dedicación de todos mis colegas del Centro de Investigación en Salud Poblacional, sin cuyo apoyo esta oportunidad no se habría hecho realidad.

Como miembro de la comunidad del INSP, es para mí un gran honor recibir de parte del Secretario de Salud, doctor Julio Frenk Mora, la responsabilidad de dirigir el rumbo futuro de esta gran institución.

La responsabilidad que ahora asumo es una tarea que implica grandes retos, pero al mismo tiempo es una oportunidad para contribuir a la consolidación del INSP. También es una oportunidad invaluable para consolidar a la salud pública como una herramienta indispensable que impulse el desarrollo que requiere el país y como un arma eficaz para luchar contra la desigualdad.

El INSP, a pesar de ser una institución joven -apenas de 17 años de edad y sin credencial para votar-es uno de los institutos de mayor prestigio del país y goza de un alto reconocimiento en el ámbito internacional. Todo esto se ha logrado gracias al esfuerzo y la dedicación de todos sus integrantes.

Nuestro Instituto surgió en enero de 1987 bajo el liderazgo visionario de Julio Frenk. En ese momento se definieron los cuatro principios de su organización, que aún se encuentran vigentes: la base conceptual de la nueva salud pública, la base de producción, la base de reproducción, y la base de utilización.

En esta nueva época que vive el país, estoy convencido de que el INSP necesita agregar un quinto principio: el de la responsabilidad social, que debe acompañar a las instituciones de salud pública. Por esta razón, durante mi gestión reorientaré las actividades de investigación hacia la solución de problemas nacionales mediante un modelo de investigación con propósito, convocando al apoyo y el compromiso de todos ustedes para luchar activamente en el abatimiento de la inequidad en salud que se observa en nuestro país.

Igualmente, durante esta nueva gestión del Instituto, alentaré la participación de toda su comunidad para inyectar nuevas perspectivas en nuestras actividades docentes y de investigación; buscaré activamente incorporar a nuestra agenda de trabajo las necesidades de nuestros usuarios. Para alcanzar la relevancia, es necesario lograr que nuestros resultados de investigación sean considerados para formular acciones y políticas que se traduzcan en mejores indicadores de salud y un sistema de salud más justo y eficiente.

He disfrutado del privilegio de colaborar de manera muy cercana con los cinco directores que ha tenido el Instituto desde su fundación. De ellos he aprendido el arte de dirigir y consensuar. Siguiendo 
su ejemplo, me propongo redoblar el esfuerzo y la dedicación en nuestras tareas para promover el desarrollo del capital humano que se requiere, con el fin de que el INSP cumpla con su misión. También actuaré bajo el compromiso de ejercer un liderazgo basado en la legitimidad, la honestidad y el ejemplo.

Dirigir nuestras actividades de investigación y docencia hacia el diseño y la implantación de acciones y políticas efectivas, implica la necesidad de identificar los principales retos que enfrentará el sector salud en los próximos años e incorporarlos en nuestra agenda de investigación. Ese conocimiento acercará al INSP hacia el cumplimiento de su misión y contribuirá a consolidarlo como una institución estratégica de consulta obligada.

La sociedad actual sufre presiones importantes, pues debe combatir la inequidad y los rezagos en salud. México experimenta una transición epidemiológica hacia el predominio de enfermedades crónico-degenerativas y neoplásicas, con una población cuya esperanza de vida al nacer va en aumento y que acusa una transición demográfica acelerada.

El envejecimiento de la población y los cada vez más costosos y complicados tratamientos seguirán siendo ejes de presión presupuestal en el corto y el mediano plazos. Esta transición demográfica y epidemiológica ocasiona ya una sobrecarga considerable en los sistemas de salud, así como un aumento progresivo en los costos de la atención.

México no escapa a la creciente amenaza de las enfermedades emergentes asociadas con la globalización, ni a los riesgos ambientales. Mientras tanto, la fuerza de trabajo de la salud pública encargada de enfrentar estos retos está insuficientemente capacitada.

Por otra parte, el Sistema Nacional de Protección Social en Salud constituye un gran paso para corregir la profunda desigualdad en cuanto a la accesibilidad de la seguridad social formal. Al igual que la reforma en salud de finales de los años 80 , que motivó la creación del Instituto, la reforma actual representa un reto y una magnífica oportunidad para el cumplimiento de nuestra misión. La diferencia entre hoy y enero de 1987 es que nuestro Instituto cuenta ahora con el capital humano preparado para responder a la exigencia poblacional y ser parte de la respuesta social organizada.

Otra oportunidad que aprovecharemos es la ubicación estratégica del Instituto en el subsector de los Institutos Nacionales de Salud. Desde este nicho podemos propiciar una muy productiva interacción con la excelencia académica que existe en estos centros y potenciar así la perspectiva de la salud pública con la experiencia de la medicina académica.
La educación en general y la educación de posgrado enfrentan retos importantes, entre los que destaca el vertiginoso avance de la informática y la globalización, lo que hace imprescindible estructurar nuevos modelos de desarrollo que involucren al Instituto no sólo con el sector salud, sino con las universidades, el sector productivo y la sociedad en general. Debemos refrendar el compromiso de innovar la calidad de la docencia y la investigación.

Juntos tenemos que consolidar y fortalecer el modelo vigente para mantenernos a la altura de las demandas que exigen esos retos. Una estrategia de mi gestión será promover el crecimiento, la capacitación y la actualización constantes de nuestros docentes para mantener con éxito un modelo innovador y de calidad que facilite nuestro desempeño institucional y promueva la diversificación de nuestra oferta educativa.

Crearemos los espacios para que nuestros alumnos encuentren un ambiente estimulante que les permita desarrollarse como investigadores o profesionales de excelencia.

Generaremos servicios que constituyan una fuente de ingresos extraordinarios, de tal modo que sea posible reducir la dependencia respecto del subsidio federal, y pondré especial interés en lograr una mejora continua de los servicios administrativos y generales de nuestro Instituto.

Estoy convencido de que con un esfuerzo compartido podremos avanzar hacia un nuevo Instituto que, sin duda, deberá seguir contribuyendo al desarrollo pleno y sano de la población, y a la eficiencia y la efectividad de los sistemas de salud.

Nuestra visión es la de un Instituto que desempeñe un papel más claro y trascendente dentro de los esfuerzos que se realizan en México para mejorar la salud de la población, abatir la inequidad en salud y promover la práctica y la enseñanza de la salud pública.

Debemos ser un Instituto preparado para enfrentar cambios e incertidumbres económicas, para reinventarse y responder a situaciones difíciles, que conozca las necesidades cambiantes de la salud de los mexicanos y de los sistemas de salud, que esté consolidado como un consultor reconocido del sector salud y del sector de la política social y que retribuya beneficios a nuestros estados anfitriones.

Debemos ser un Instituto que rinda cuentas de manera responsable y oportuna y que traduzca los resultados de investigación en acciones y políticas de salud; que opere con una visión de género; que cuente con programas de enseñanza para fomentar la educación continua y la capacitación mediante los recursos más modernos. 
Antes de terminar, quisiera hacer algunas reflexiones adicionales.

El relevo de liderazgo nos ofrece un motivo para iniciar un nuevo pacto institucional, un nuevo compromiso con nuestras actividades diarias. Trabajaremos para lograr que la visión que nos proponemos sea una visión compartida por todo el personal del INSP. Trabajaremos para cambiar la percepción sobre las actividades de evaluación y rendición de cuentas, con el fin de convertirlas en un instrumento que aliente el desarrollo personal y mejore el desempeño institucional. Promoveremos un sistema de contratación y evaluación transparente.

Trabajaremos con base en una cultura cooperativa, propiciaremos el diálogo y crearemos espacios abiertos que favorezcan las relaciones interpersonales, de tal manera que nuestra comunidad evolucione de un pasado fragmentado a un futuro compartido.

Este día no celebro un triunfo, celebro con gran alegría el resultado de un proceso académico, democrático y transparente. En este proceso todos en el INSP hemos crecido, hemos madurado. Me daré a la tarea de recoger las excelentes e innovadoras propuestas de los doctores Olaiz Fernández y González Block, quienes, siguiendo la tradición institucional de considerar que lo producido en el INSP es un bien público, generosamente han compartido sus ideas, reflexiones y propuestas. Ahora me tocará a mí conjuntarlas con las propias y con las de nuestra comunidad.

Sin embargo, todo nuestro trabajo y esfuerzo, así como la oportunidad que nos brinda el liderazgo re- novado, sólo podrán cristalizar en la medida en que ustedes, los tomadores de decisiones, los que hacen las políticas y conducen los programas de salud, nos incorporen en sus planes con el propósito de lograr las sinergias necesarias para avanzar en salud y lograr el fin último de la salud pública: el desarrollo pleno y sano de todos los miembros de la sociedad.

Este nuevo reto representa para mí un esfuerzo personal adicional, por lo que de antemano le pido comprensión a mi esposa Isabelle y a mis hijos Alfonso, Mateo y Alejandro por las ausencias que esta nueva responsabilidad significará al interior de nuestro hogar. Es gracias a ellos, al apoyo y al amor que recibo cotidianamente, como he podido avanzar exitosamente en mi vida profesional.

Quisiera terminar citando al poeta y dramaturgo alemán Johann Wolfgang von Goethe:

no basta saber, se debe también aplicar.

No es suficiente querer, se debe también hacer.

Señor Secretario, comunidad toda del INSP: acepto con enorme entusiasmo el reto de dirigir esta gran institución.

Muchas gracias.

Dr. Mauricio Hernández Avila Director General del Instituto Nacional de Salud Pública Cuernavaca, Morelos, México, 2 de abril de 2004 